\title{
Investigations of the Aftershocks of July 4, 1968 Earthquake in Epidavros (*)
}

\author{
J. C. DRAKOPOULOS (**) - H. X. SRITASTAVA (***) \\ Ricevuto il 25 Febbraio 1970
}

\begin{abstract}
SUmary. - The spatial and the time distribution of the aftershocks of the earthquake of July 4, 1968 in Epidavros (Greece) has been studied. It was found that the value of $b$ in Gutenberg-Richter's relationship was nearly the same for the primary as well as the secondary or second order aftershocks of the sequence. The focal mechanism of the second order aftershocks as observed from the sense of first motion of $P$-waves showed some difference from that of the main shock or its primary aftershock.
\end{abstract}

Riassunto. - $\mathrm{E}$ stata studiata la distribuzione nello spazio e nel tempo delle repliche del terremoto del 4 Luglio 1968, avvenuto ad Epirlavros (Grecia). Per b nella relazione di Gutenberg-Richter, è stato trovato un valore pressocché uguale sia per le repliche primarie che per quelle secondarie (o del secondo ordine) della sequenza. Il meccanismo all'ipocentro delle repliche del secondo ordine, a seconda del verso delle onde $P$, ha mostrato aleune differenze da quello della scossa principale o della sua replica primaria.

\section{1. - TNTRoDUCTION.}

Study of aftershocks of an earthquake may possibly provide important clues for solving the mechanism of earthquake occurrence. With this end in view, some statistical features such as geographical,

(*) International Institute of Seismology and Earthqualie Engineering, Tokyo, Japan.

(**) Seismological Laboratory, Athens University, Greece.

(***) India Meteorological Department, Locli Road, New Delli-3, India. 
temporal and magnitude distributions of aftershocks are being extensively investigated ( ${ }^{1}$. Although a fow statistical laws on the occurrence of aftershocks are fairly well known, the detailed characteristics of the sequence of aftershocks vary markedly from one region to the other. On this account, the nature of aftershocks is far from completely understood, particularly for formulating any theory for earthquake prediction. The deformation and stress characteristics of the aftershocks enable us to investigate the properties of the Earth's structure, thus emphasizing a detailed study of individual set of aftershocks over as many different regions of the Earth as possible. Another reason for the study of the aftershocks of the natural earthquakes follows from the fact that their characteristies generally differ from those of artificial earthquakes e.g. explosions which have otherwise contributed significantly to the science of seismology.

The object of this paper is therefore, to further our knowledge on the occurrence of aftershocks in Greece in order to study their distinctive characteristics and to deduce some physical properties of the Earth's structure from their deformation characteristics. The focal mechanism of aftershocks has also been tentatively explained on the basis of available data.

2. - DESCRIPTION OF THE MAIN SHOCK OF JULY 4, 1968 IN GREECF.

At 21 hours 48 minutes GMT on July 4, 1968, a shallow earthquake of magnitude, $M_{L}=5.0$ occurred with its epicentre at Lat. $37.7^{\circ} \mathrm{N}$ and Long. 23.20 $\mathrm{E}$ in Greece. The epicentral distance of this shocks was $60 \mathrm{~km}$ southwest of the standardized U.S.C.G.S. station of $\Lambda$ thens University. On account of the short epicentral distance of this recording station which is in the centre of Greek Seismological network, a large number of aftershocks of small magnitude were recorded. The focal depth of the main shock by macroseismic data was $30 \mathrm{~km}$, but there are some indications as discussed later that this depth was probably less than $30 \mathrm{~km}$. Following the main shock, there were more than 300 aftershocks recorded with their magnitudes between 2.2 and 4 . Only one foreshock of magnitude $M_{L}-2.8$, was recorded about ten hour's prior to the occurrence of the main shock.

The maximum intensity in modified Mercalli scale was VII for the main shock. Substantial property damage was caused due to this earthquake in the region of Argolis, particularly in Epidavros. Ac- 
cording to the press reports, 5 houses collapsed, about 36 were seriously damaged and 64 houses were slightly damaged. Earthslumping was observed in New Epidavros.

It may be interesting to note that the epicentre of the main shock was located in the region which is not characterized by high seismic

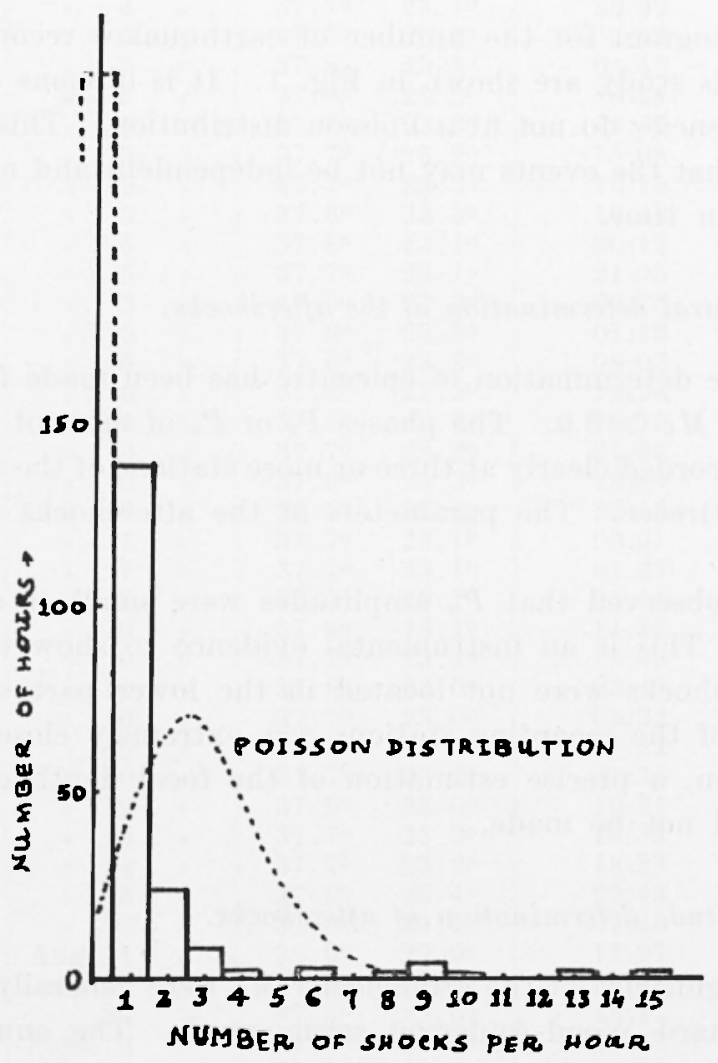

lig. 1 - The number of hours during which zero through 15 shocks were recorded and the corresponding Poisson distribution. A test for goodness of fit indicated marked disagreement.

activity. From the seismicity studies $\left(^{2}\right)$, it is seen that only 21 earthquakes of magnitude larger than 5 have been recorded since 1922. Out of these, three shocks had their focal depth larger than $100 \mathrm{~km}$. It is remarkable to find that none of the shocks in the region except one was accompanied by aftershocks or preceded by foreshocks. Even that shock had only 6 to 8 foreshocks and aftershocks. Considering 
all these aspects, it is obvious that the main shock of July 4, 1968 had distinctive characteristics in so far as the seismicity of the region is concerned.

\section{3. - ANALYSis OF DATA.}

The histogram for the number of earthquakes recorded and included in this study are shown in Fig. 1. It is obvious that the observed frequencies do not fit a Poisson distribution. This may be due to the fact that the events may not be independent and not randomly distributed in time.

\section{1 - Epicentral determination of the aftershocks.}

Accurate determination of epicentre has been made for all earthquakes with $M_{L} \geqslant 3.0$. The phases $P_{g}$ or $P_{n}{ }_{n}$ of most of these shocks have been recorded clearly at three or more stations of the seismological network of Greece. The parameters of the aftershocks are given in Table I.

It was observed that $P_{n}$ amplitudes were small as compared to that of $P_{g}$. This is an instrumental evidence to show that the foci of the aftershocks were not located in the lower part of the crust. Since none of the recording stations was extremely close to the epicentral region, a precise estimation of the focal depth of the aftershocks could not be mate.

\section{2 - Magnitude determination of aftershocks.}

The magnitudes of the aftershocks $M_{L}$ were generally determined by the standard Wood-Anderson seismograph. The cumulative frequency of the aftershocks for different values of $M_{L}$ are given in Table II.

4. - RESTITS AND DISCUSSION.

4.1 - Time distribution of aftershocks.

The time distribution of aftershocks has been studied by many Japanese investigators. The original Omori's law was modified ( ${ }^{3}$ ) as

$$
n(t) d t=k(t+c)^{\cdot h} d t
$$


Table I - AFtershocks of $1 t_{L} \geqslant 3.0$

\begin{tabular}{|c|c|c|c|c|c|c|c|}
\hline \multirow{2}{*}{$\frac{\text { No }}{\text { Main shock }}$} & \multicolumn{3}{|c|}{ Date } & \multirow{2}{*}{$\begin{array}{l}\text { Lat. } \\
N \\
37.7^{\circ}\end{array}$} & \multirow{2}{*}{$\begin{array}{l}\text { Jong. } \\
E \\
23.2^{\circ}\end{array}$} & \multirow{2}{*}{$\begin{array}{c}\text { Arrival time at } \\
\text { A thens } \\
\text { (approximately) } \\
21: 48\end{array}$} & \multirow{2}{*}{$\begin{array}{c}\text { Magnitude } \\
M_{L} \\
\overline{\mathbf{j}} .0\end{array}$} \\
\hline & July & 4 & 1968 & & & & \\
\hline & July & 4 & 1968 & $37.6^{\circ}$ & 23.10 & $22: 42$ & 3.0 \\
\hline 2 & " & 4 & " & $37.7^{\circ}$ & $23.2^{\circ}$ & $23: 04$ & 3.2 \\
\hline 3 & $"$ & 4 & $"$ & $37.7^{\circ}$ & 23.10 & $23: 28$ & 3.0 \\
\hline+ & " & + & $"$ & $37.7^{\circ}$ & $23.1^{\circ}$ & $23: 33$ & 3.0 \\
\hline 5) & " & 5 & $"$ & $37.7^{\circ}$ & $23.2^{\circ}$ & $02: 13$ & 3.1 \\
\hline 6 & $"$ & 5) & $"$ & $37.8^{\circ}$ & $23.2^{\circ}$ & $04: 43$ & 3.4 \\
\hline 7 & $n$ & 5 & $"$ & 37.80 & $23.2^{\circ}$ & $10: 28$ & 3.2 \\
\hline 8 & $"$ & 5 & $"$ & $37.7^{\circ}$ & $23.3^{\circ}$ & $14: 57$ & 3.1 \\
\hline 9 & $"$ & 5 & $"$ & $37.7^{\circ}$ & $23.2^{0}$ & $15: 08$ & 3.6 \\
\hline 10 & $"$ & 5 & $"$ & $37.7^{\circ}$ & 23.30 & $15: 15$ & 3.3 \\
\hline 11 & $"$ & 5 & $"$ & $37.6^{\circ}$ & $23.3^{0}$ & $17: 49$ & 3.3 \\
\hline 12 & $"$ & 5 & $"$ & 37.80 & 23.10 & $20: 12$ & 3.0 \\
\hline 13 & $"$ & 5 & $"$ & $37.7^{\circ}$ & $23.1^{\circ}$ & $21: 05$ & 3.0 \\
\hline 14 & $"$ & 5 & $"$ & $37.6^{\circ}$ & $23.3^{0}$ & $22: 25$ & 3.1 \\
\hline i5 & $"$ & 6 & $"$ & $37.6^{\circ}$ & $23.3^{\circ}$ & $01: 13$ & 3.0 \\
\hline 16 & $"$ & 6 & $"$ & $37.6^{\circ}$ & $23.3^{0}$ & $08: 03$ & 3.1 \\
\hline 17 & $"$ & 6 & $"$ & $37.6^{\circ}$ & $23.3^{\circ}$ & $16: 26$ & 3.5 \\
\hline 18 & $"$ & 6 & $"$ & $37.6^{\circ}$ & $23.3^{0}$ & $19: 45$ & 3.1 \\
\hline 19 & $"$ & 6 & $"$ & $37.7^{\circ}$ & $23.2^{0}$ & $21: 55$ & 3.9 \\
\hline 20 & $"$ & 6 & $"$ & $37.6^{\circ}$ & 23.30 & $22: 20$ & 3.3 \\
\hline 21 & $n$ & 6 & $"$ & $37.7^{\circ}$ & $23.3^{0}$ & $22: 43$ & 3.2 \\
\hline 22 & $"$ & 7 & $"$ & $37.7^{\circ}$ & 23.10 & $00: 51$ & 3.7 \\
\hline 23 & $"$ & 7 & $"$ & $37.7^{\circ}$ & 23.10 & $01: 27$ & 3.0 \\
\hline 24 & $"$ & 7 & $"$ & $37.7^{\circ}$ & $23.1^{\circ}$ & $0 \overline{5}: 44$ & 3.5 \\
\hline 25 & $"$ & 9 & $"$ & $37.8^{\circ}$ & 23.10 & $14: 32$ & 3.0 \\
\hline 26 & $"$ & 9 & $"$ & $37.7^{\circ}$ & $23.2^{\circ}$ & $16: 49$ & 3.0 \\
\hline 27 & " & 10 & $"$ & $37.8^{\circ}$ & 23.00 & $03: 48$ & 3.5 \\
\hline 28 & $"$ & 10 & $"$ & $37.7^{\circ}$ & $23.0^{\circ}$ & $05: 32$ & 3.0 \\
\hline 29 & $"$ & 10 & $"$ & 37.80 & $23.0^{\circ}$ & $16: 22$ & 3.0 \\
\hline 30 & $"$ & 10 & $"$ & $37.7^{\circ}$ & $23.2^{0}$ & $21: 36$ & 3.4 \\
\hline 31 & $"$ & 12 & $"$ & $37.9^{\circ}$ & $23.0^{\circ}$ & $10: 21$ & 3.1 \\
\hline 32 & $"$ & 13 & " & $37.7^{\circ}$ & $23.3^{\circ}$ & $19: 38$ & 3.4 \\
\hline 33 & $"$ & 14 & $"$ & $37.7^{\circ}$ & $23.2^{\circ}$ & $18: 33$ & 3.7 \\
\hline 34 & $n$ & 16 & $"$ & $37.6^{\circ}$ & $23.4^{\circ}$ & $22: 43$ & 3.0 \\
\hline 35 & " : & 22 & $"$ & $37.6^{\circ}$ & 23.40 & $07: 46$ & 4.0 \\
\hline 36 & Alug. & 1 & $n$ & $38.0^{\circ}$ & $22.9^{\circ}$ & $12: 27$ & 3.0 \\
\hline 37 & " & 10 & $"$ & $37.9^{\circ}$ & 23.10 & $08: 44$ & 3.3 \\
\hline 38 & & 24 & $"$ & $37.5^{\circ}$ & 23.50 & $18: 17$ & 3.2 \\
\hline 39 & Sept. & 3 & $"$ & 37.40 & 23.50 & $03: 57$ & 3.0 \\
\hline 40 & " & 3 & $"$ & 37.70 & 23.00 & $22: 59$ & 3.1 \\
\hline+1 & $"$ & 12 & " & $37.8^{\circ}$ & $23.2^{\circ}$ & $10: 36$ & 3.5 \\
\hline 42 & $"$ & 18 & $"$ & $37.5^{\circ}$ & $23.4^{\circ}$ & $14: 26$ & 3.2 \\
\hline 43 & & 22 & $"$ & $37.8^{\circ}$ & $23.3^{\circ}$ & $09: 5 \overline{5}$ & 3.0 \\
\hline 44 & & 26 & $"$ & 37.80 & $23.0^{\circ}$ & $00: 59$ & 3.2 \\
\hline 45 & oet. & 14 & $n$ & $37.6^{\circ}$ & $23.3^{0}$ & $01: 42$ & 4.0 \\
\hline 46 & & 14 & $"$ & $37.9^{\circ}$ & $23.2^{\circ}$ & $17: 08$ & 3.4 \\
\hline 47 & & 23 & $n$ & $37.7^{\circ}$ & $23.4^{0}$ & $05: 17$ & 3.0 \\
\hline 48 & & 23 & $"$ & $37.8^{\circ}$ & 23.10 & $12: 20$ & 3.1 \\
\hline 49 & & 23 & $"$ & $38.2^{\circ}$ & $22.9^{\circ}$ & $22: 32$ & 3.0 \\
\hline 50 & & 24 & $"$ & 37.60 & 23.30 & (0) $1: 26$ & 3.6 \\
\hline 51 & & 26 & $"$ & $37.6^{\circ}$ & 23.40 & $06: 27$ & 3.1 \\
\hline 52 & Nov. & 2 & $n$ & $37.6^{\circ}$ & $23.3^{\circ}$ & $22: 58$ & 3.1 \\
\hline 53 & 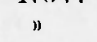 & 2 & $"$ & $37.6^{\circ}$ & 23.20 & $05: 17$ & 3.3 \\
\hline
\end{tabular}


Tablo II - Cumulative Frequency

\begin{tabular}{|c|c|}
\hline OF AFTERSHOCKS & VERSUS \\
\hline$M_{L}$ & $\begin{array}{c}\text { Cumulative } \\
\text { frequency }\end{array}$ \\
\hline & \\
2.2 & 308 \\
2.3 & 277 \\
2.4 & 243 \\
2.5 & 193 \\
2.6 & 157 \\
2.7 & 120 \\
2.8 & 91 \\
2.9 & 71 \\
3.0 & 53 \\
3.1 & 36 \\
3.2 & 26 \\
3.3 & 20 \\
3.4 & 15 \\
3.5 & 11 \\
3.6 & 7 \\
3.7 & 5 \\
3.8 & 3 \\
3.9 & 3 \\
4.0 & 2 \\
\hline
\end{tabular}

where $t$ is the time after the main shock, $n(t) d t$ is the number of aftershocks occurring in the time interval $t$ and $t+d t$ and $k, c$ and $h$ are constant chosen to fit the data. When $h=1$, the equation [1] expresses the Omori's law. Mogi (*) showed that the time distribution of aftershocks in the early stage after the occurrence of the main shock is expressed by the relation

$$
n(t) d t=n_{\imath} t^{h} d t \quad 0<t<t_{0}
$$

where $n_{l}$ is a constant.

Drakopoulos $\left(^{(5)}\right.$ determined the cumulative frequency of many earthquakes in Greece using

$$
N(t)=\int_{i}^{t_{0}} n_{l}(t) d t .
$$

This author found that the functions of the following type fit the data

$$
N=N_{t} t^{-H} \quad t<t_{0}
$$

or

$$
\log N=B-H \log t
$$




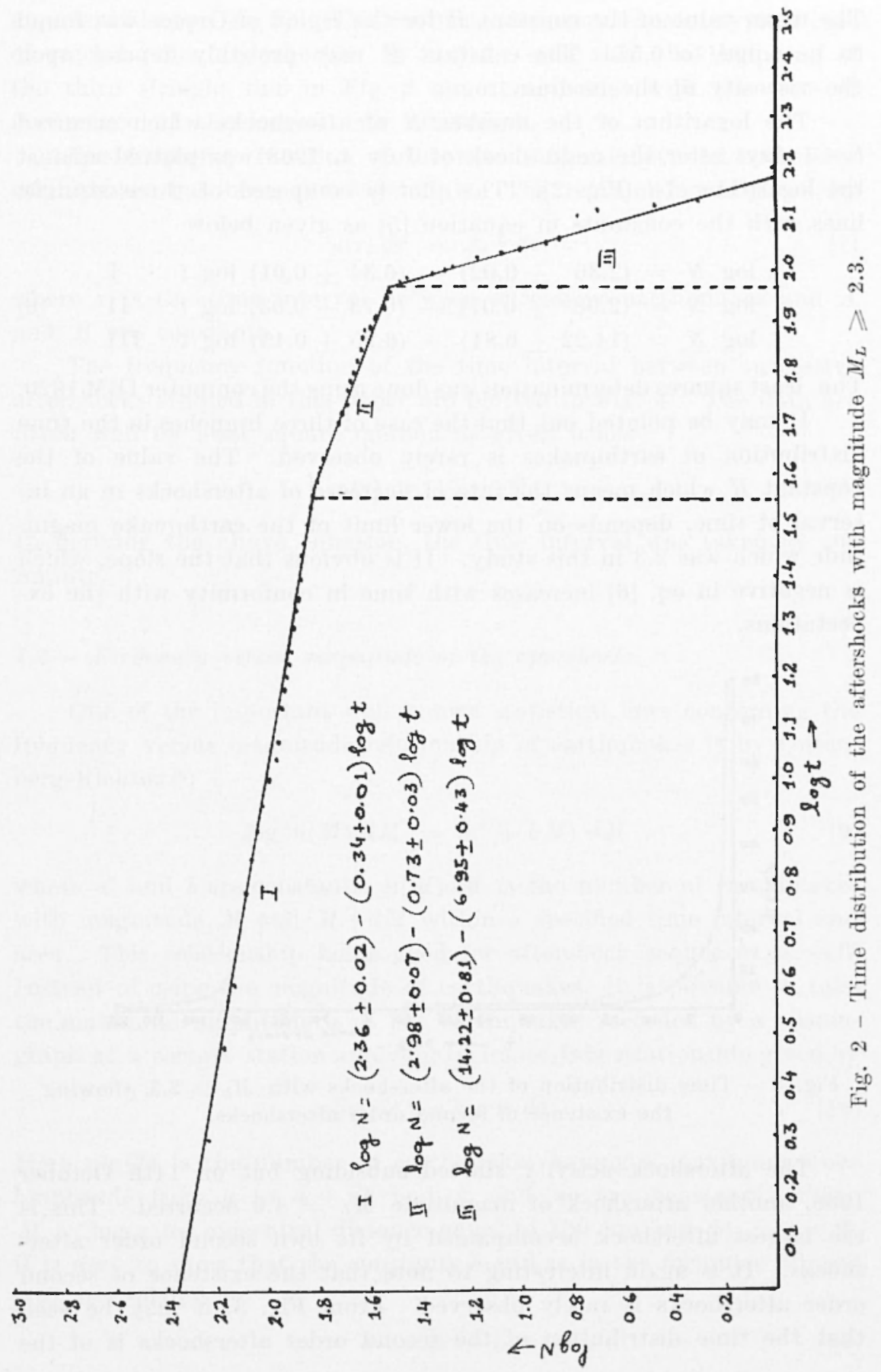


The mean value of the constant $H$ for the region of Greece was found to be equal to 0.5\%. The constant $H$ may probably depend upon the viscosity of the medium.

The logarithm of the number $X$ of aftershocks which occurred $t$-- 1 days after the main shock of July +, 1968 was plotted against the logarithm of $t$ (Fig. 2). This plot is composed of three straight lines with the constants in equation [5] as given below

$$
\begin{aligned}
& \log N=(2.36 \pm 0.02)-(0.34 \pm 0.01) \log t \\
& \log N=(2.98 \pm 0.07)-(0.73 \pm 0.03) \log t \\
& \log N=(14.22 \pm 0.81)-(6.95 \pm 0.43) \log t
\end{aligned}
$$

The least squares determination was done using the computer IBM 1620 .

It may be pointed out that the ase of three branches in the time distribution of earthquakes is rarely observed. The value of the constant $B$ which means the rate of decrease of aftershocks in an interval of time, depends on the lower limit of the earthquake magnitude which was 2.3 in this study. It is obvious that the slope, which is negative in eq. [6] increases with time in conformity with the expectations.

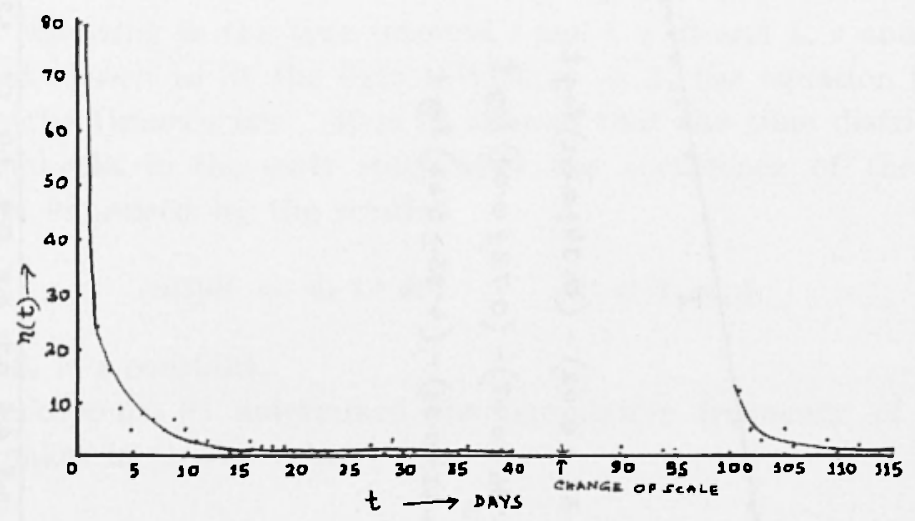

Fig. 3 - Time distribution of the aftershocks with $y_{l} \geqslant 2.3$, showing the existence of second order aftershocks.

The aftershock activity started subsiding but on 1 th October 1968 , another aftershock of magnitude $M_{L}=4.0$ occurred. This is the largest aftershock accompanied by its own second order aftershocks. It is again interesting to note that the existence of second order aftershocks is rarely observed. From Fig. 3, it may be seen that the time distribution of the second order aftershocks is of the 
exponential type [eq.2]. This contirms the occurrence of typical case of second order aftershocks. It may be seen that the beginning of the third straight line in Fig. 2 almost coincides with the time of occurrence of the lawgest late aftershock.

The frequency function of the time interval between successive earthquakes has been investigated $\left(^{3}\right)$. The relationship is given by

$$
u(\tau) d \tau=A e^{-B} d \tau
$$

where $\tau$ is the time interval between successive earthquakes and $A$ and $B$ are constants.

The frequency function of the time interval between successive aftershocks studied in this paper are plotted in Fig. 4 . The data are fitted well by least square method as given below

$$
n(\tau)=17 \tau^{-0.75}
$$

In deriving the above equation, the time interval was taken as one minute.

\section{2 - Fiequeney versus magmitude of the aftershocks.}

One of the important well known statistical laws concerning the frequency versus magnitude relationship of earthquakes is by Gutenberg-Richter ( $\left.{ }^{6}\right)$

$$
\log n(W) d H=\left(a^{\prime}-b \cdot h\right) d u
$$

where $a$ and $b$ are constants, $n(M) d M$ is the number of earthquakes with magnitude $M$ and $M+d M$ within a specified time interval and area. This relationship holds good for aftershock sequences as well. Instead of using the magnitude of earthquakes, it is possible to take the maximum amplitude $a$ of the earthquakes recorded by a seismograph at a certain station applying Ishimoto-Iida relationship given by

$$
n(a) d a=k: a^{-m} d a \text {. }
$$

Here $n(a)$ da is the number of earthquakes having a maximum trace amplitude from $a$ to $a+d a$ and $k$ and $m$ are constants. Since $M=\log$ a for epicentral distance equal to $100 \mathrm{~km}$ and da - $1 \mathrm{~d} \boldsymbol{m}$. it is easy to show that the constants $b$ and $m$ in the formulae $[9]$ and [10] are related by

$$
b=m-1 \text {. }
$$




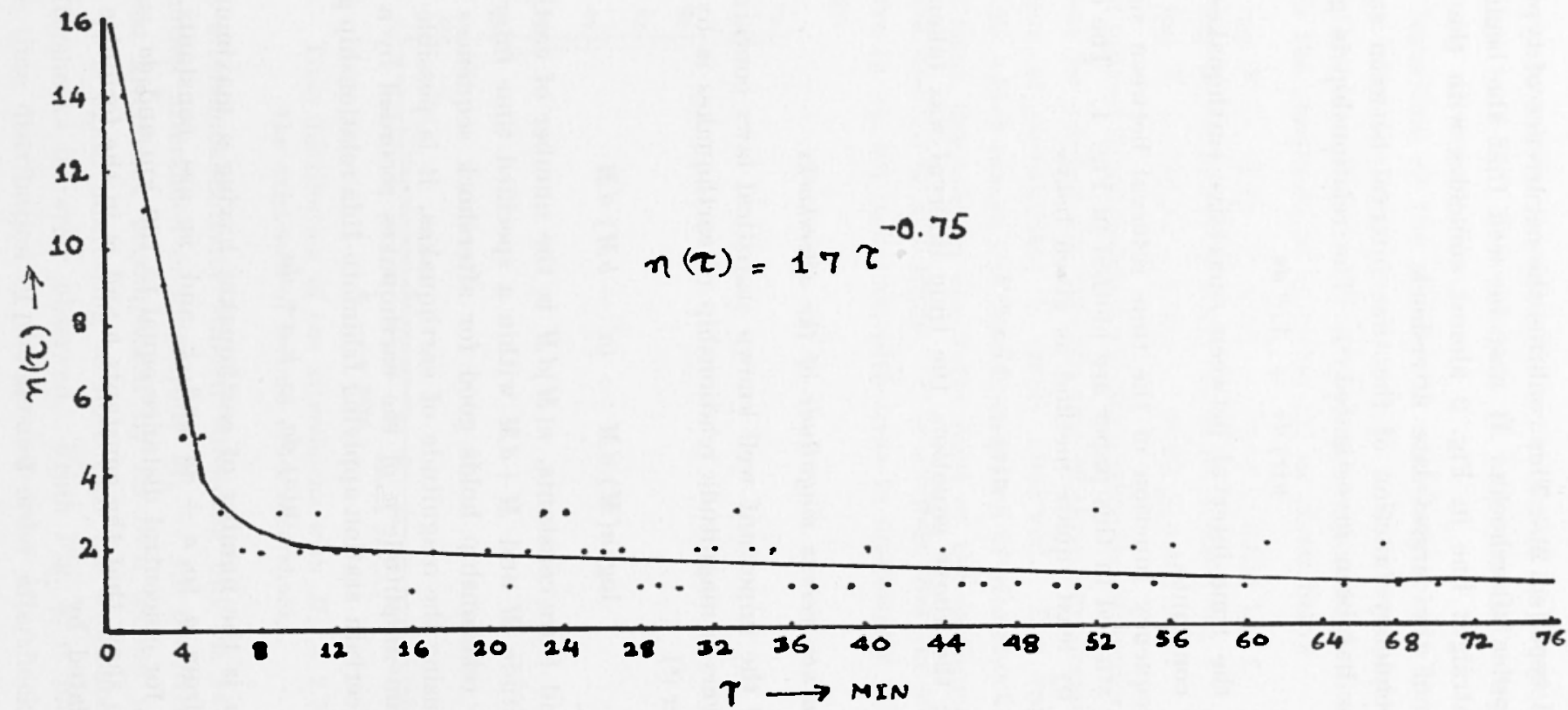

Fig. 4 - Frequency function of the time interval between successive aftershocks. 
Instead of using equation [8], many investigators use the cumulative frequency function expressed by

$$
\log N=a-b M
$$

The constant $b$ of this equation is related to the tectonic structure of the seismic region. Mogi ( $\left.{ }^{7}\right)$ showed experimentally, that this constant depends on the homogeneity of the material in the seismic region and on the distribution of the applied stress. The value of $b$ increases as the degree of heterogeneity increases and as the degree of symmetry of the applied stress decreases. Mogi has also found that the slope $b$ for microfracturing in rock samples is similar to that obtained in the seismicity of the Earth. A decrease of $b$ with focal depth has been observed by several seismologists $\left({ }^{8,9,10}\right)$. Based on many aftershock sequences, Drakopoulos (5) found the value of $b$ between 0.4 and 1.7 and inferred that its variation is more marked in the vertical as compared to that in the plane parallel to the surface of the Earth. Many seismologists ("1) have found that the value of $b$ is larger for aftershocks as compared to that for foreshocks. Mogi ( $\left.{ }^{12}\right)$ showed experimentally that when foreshocks and aftershocks occur in the same region, the value of $b$ is smaller for foreshocks than for aftershocks, because the main shock causes new cracks and thus the number of irregular points increases. Drakopoulos (5) found that the constants $b_{f}$ and $b_{a}$ of the foreshock and the aftershock sequences of the same main shock are connected by the relation

$$
b_{f}=(0.11 \pm 0.13)+(0.65 \pm 0.11) b_{a}
$$

This anthor has also found that the value of $b$ for foreshock and aftershock sequences has a tendency to decrease with the magnitude of the main shock.

The logarithm of the cumulative frequency function $N(M)$ versus the magnitude $M$ of the aftershocks of the Epidavros earthquake is plotted in the Fig. 5. The following relation was obtained by the least squares method,

$$
\log N=(5.44 \pm 0.0 \tau)-(1.25 \pm 0.02) M
$$

The same value of $b$ was obtained using the relationship by Utsu $\left({ }^{13}\right)$

$$
b=0.4343 /\left(M^{\prime}-M_{m i n}\right)
$$


where $W^{\prime}$ is the average magnitude for the series and $H_{m i n}$ is the minimum magnitude.

The value of $b$ for this sequence is rather large and is attributed to the small focal depth of the aftershocks.

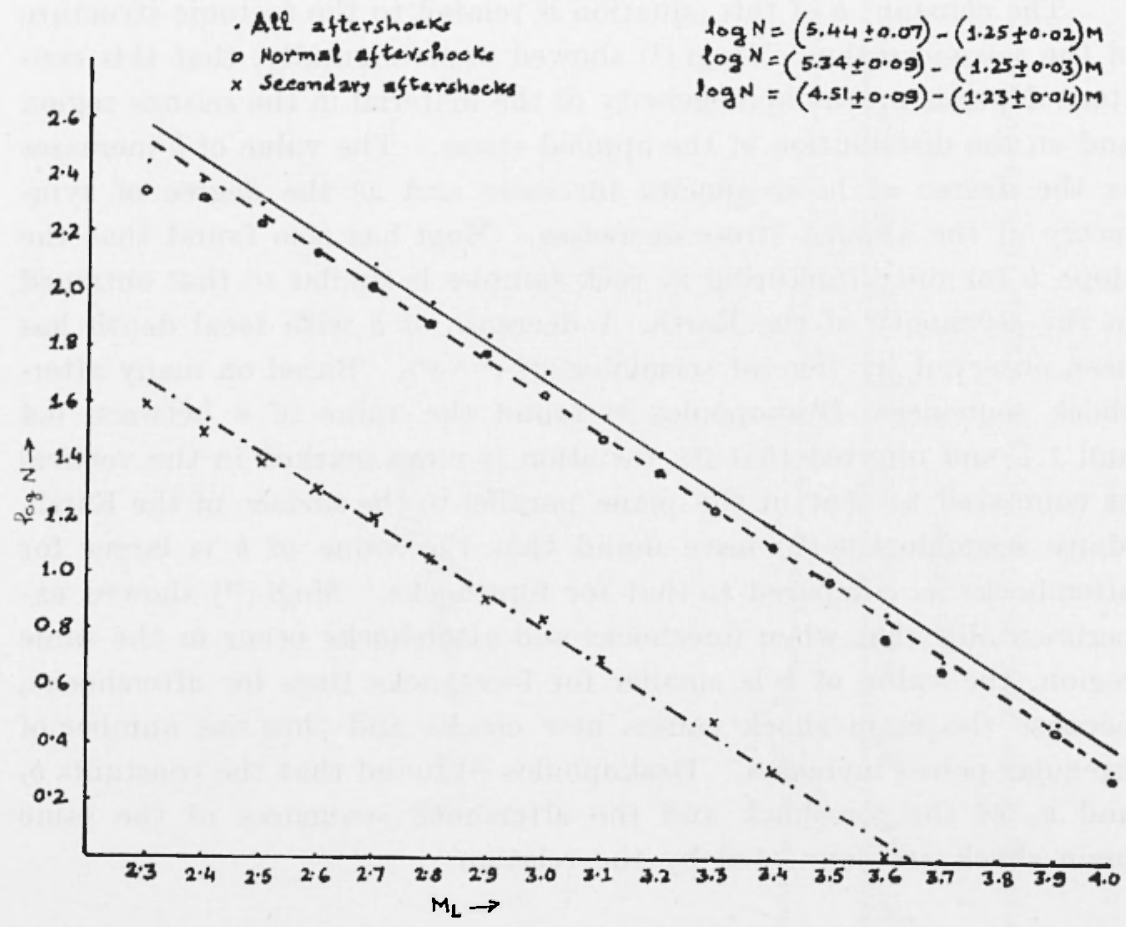

Fig. 5 - Cumulative frequency function of the magnitude of aftershocks.

The magnitude distribution of the second order aftershocks which occurred after 14 th October was examined separately. The relationship between $\log N^{\top}$ versus $M$ is given by

$$
\log N=(4.51 \pm 0.09)-(1.23 \pm 0.04) M .
$$

The magnitude distribution of the aftershocks excluding the second order aftershocks is expressed by

$$
\log N=(5.34 \pm 0.09)-(1.25 \pm 0.03) M .
$$

It may be noted thus that the value of $b$ remains more or less the same as found previously i.e. $b=1.25$. This is quite reasonable 
because the value of $b$ is related to the tectonic structure of the region. It may also be inferred that there was no migration of seismic activity in the vertical direction otherwise the value of $b$ being dependent upon the focal depth would have been changed. All the relations discussed above for this sequence of the aftershocks hold good for $M_{t} \geqslant 2.3$.

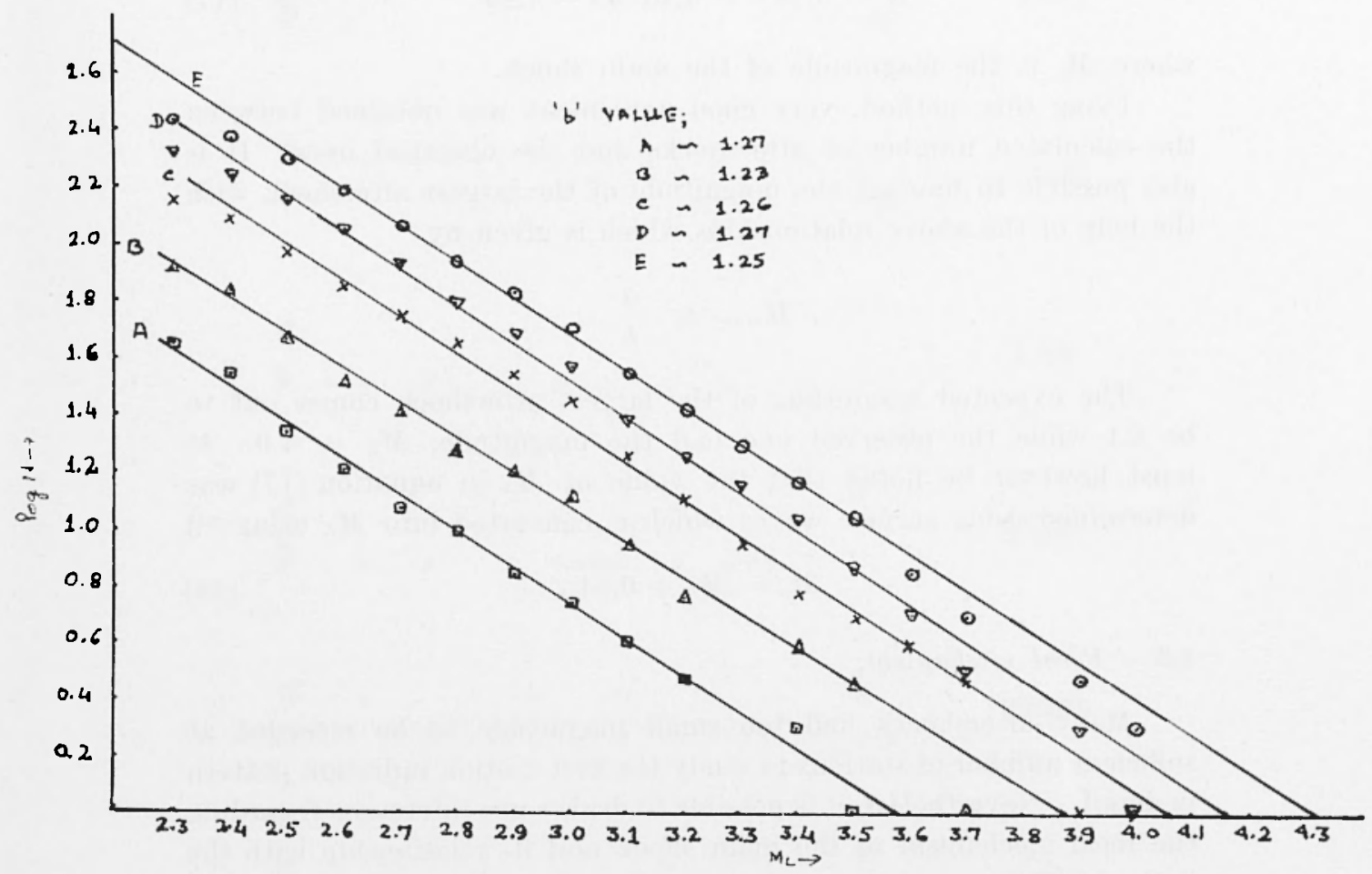

Fig. 6 - Cumulative frequency distribution of magnitude for some different time intervals after the occurrence of the main shock.

The magnitude frequency relationship for the aftershocks for various periods of time is shown in Fig. 6. Here $N(M I)$ is the cumulative frequency i.e. the number of shocks with magnitude $\geqslant M_{L}$. Tho plots marked with the letters $A, B, C, D$ and $E$ indicate the various periods of time. It may be seen that these lines are more or less parallel, signifying that the value of $b$ remains constant with time. It appears thus possible to estimate the values of $b$ only a few minutes or hours after the occurrence of the main shock without waiting till the end of the sequence. Knowing $b$ it is relatively easy to antici- 
pate the number of aftershocks which may be expected in the order of magnitudes, using the relationship

$$
\log N=a-b . M
$$

since the constant $a$ may be calculated from the equation $\left(^{5}\right)$

$$
a=3.64 b+0.48 M_{0}-1.49
$$

where $y_{o}$ is the magnitude of the main shock.

Using this method, very good agreement was obtained between the calculated number of aftershocks and the observed ones. It is also possible to forecast the magnitude of the largest aftershock with the help of the above relationships which is given by

$$
H_{m a x}=-\frac{a}{i} \text {. }
$$

The expected magnitude of the largest aftershork comes out to be 4.1 while the observed one had the magnitude, $M_{L}=4.0$. It must, however be noted that the value of $M_{o}$ in equation [17] was determined using surface waves which is converted into $M_{L}$ using $\left.{ }^{(14}\right)$

$$
M_{s}=M_{L}+0.44 \text {. }
$$

\section{3 - Focal mechanism.}

Many aftershocks had too small masnitude to be recorded at sufficient number of stations to study the first motion radiation pattern in detail. Nevertheless, it is possible to draw some inferences regarding the focal mechanism of the main shock and its relationship with the first and the second order aftershocks. The relative changes in the focal mechanism may be observed simply by noting the sense of first motion at a given number of stations throughout the aftershock sequence. Fig. $T$ shows the sense of first motion (where measurable) at eight stations of Greece during the aftershock period. It may be noted that the sense of first motion remains rather unchanged throughout the sequence except after 98 days (indicated by arrows). This suggests that the focal mechanism of shocks in this sequence is related to that of the main shock. This is confirmed by the results of Udias $\left({ }^{15}\right)$, Mc Evilly $\left({ }^{16}\right)$ and Pshennikov $\left({ }^{17}\right)$. However, the second order aftershocks have a focal mechanism which is different from that of the main shock. 


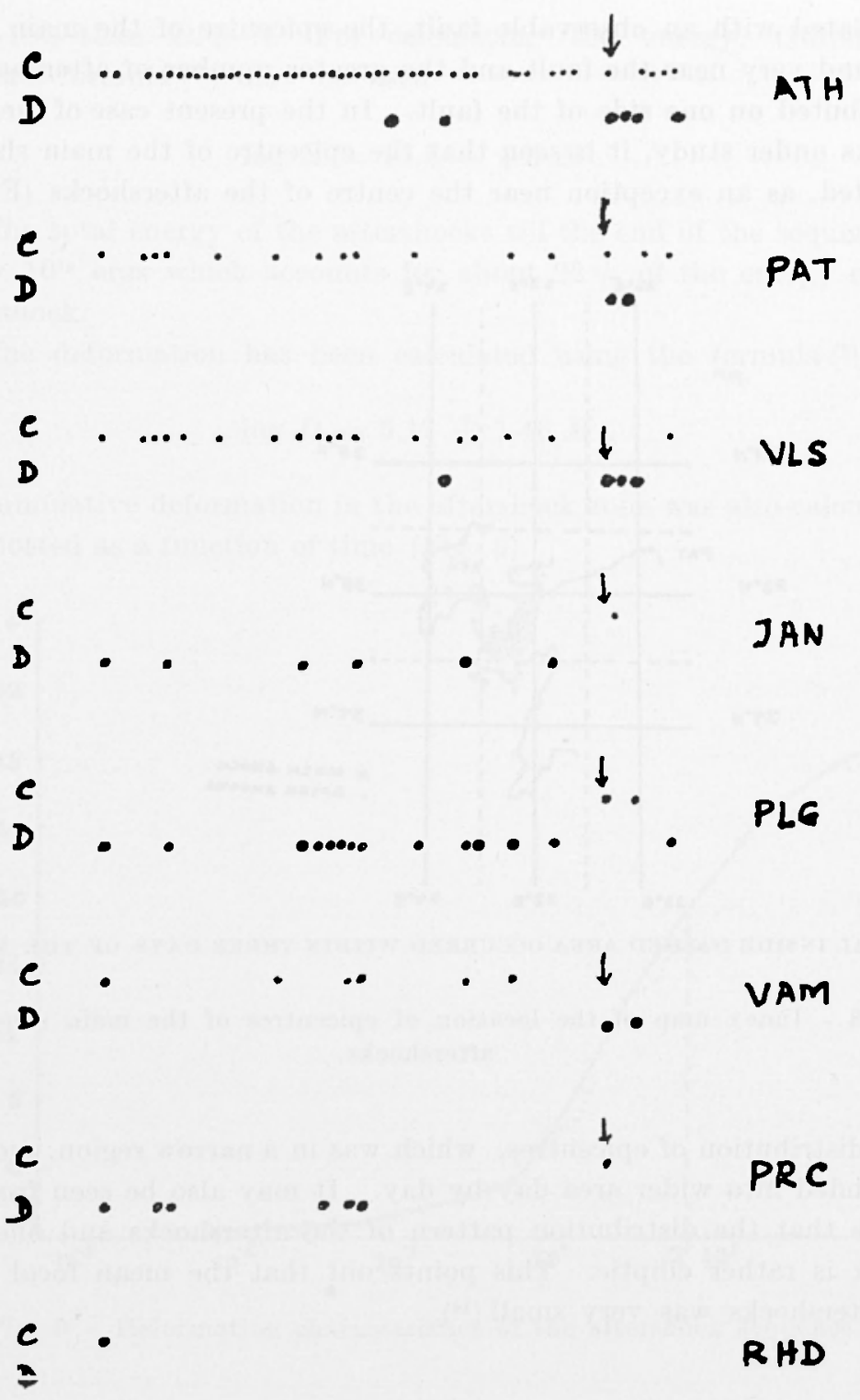

Fig. 7 - First motion sense of the aftershocks at the Greek Seismological Network.

4.4 - Areal distribution of aftershocks.

Matuzawa (18) pointed out that the epicentre of the main shock is often near the edge of the aftershocks area. In the case of earthquakes 
associated with an observable fanlt. the epicentre of the main shock is found very near the fault and the greater number of aftershoeks is distributed on one side of the fault. In the present rase of the aftershocks under study, it is seen that the epicentre of the main shock is situated, as an exception near the centre of the aftershocks (Fig. 8).

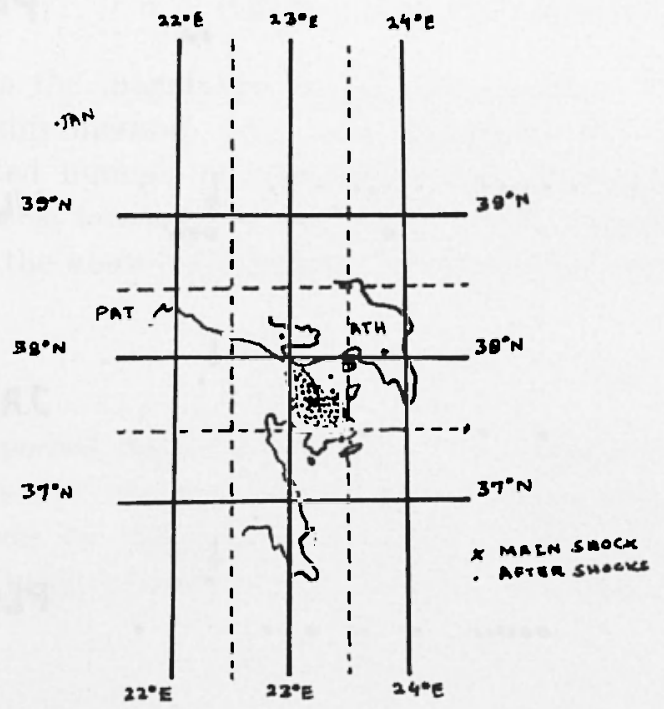

EPICENTRAL INEIDE DASIIED AREA OCCURRED WITIIN TIREE DAYS OF TIE MAIN SHOCK

Fig. 8 - Index map of the location of epicentres of the main shock and aftershocks.

The distribution of epicentres, which was in a narrow region, suddenly expanded into wider area day by day. It may also be seen from the figure that the distribution pattern of the aftershocks and one foreshock is rather elliptic. This points out that the mean focal depth of aftershocks was very small $\left({ }^{19}\right)$.

\section{5 - Aftershock activity and deformation characteristics.}

The aftershock activity of an earthquake is indicated by the ratio of the total energy of aftershocks $E_{a}$ to the energy of the main shock $E_{o}$. Instead, $M_{0}-M_{1}$ may be used as a rough measure of the aftershock activity. For some cases, $E_{a}$ exceeds $E_{0}$ while usually 
$E_{a}$ is less than $\left.E_{o}{ }^{(5,13}\right)$. For calculating the energy, GutenbergRichter's formula (20) may be used

$$
\log E=11.8+1.5 M
$$

The total energy of the aftershocks till the end of the sequence is $17.6 \times 10^{18}$ ergs which accomts for about $22 \%$ of the energy of the main shock.

The deformation has been calculated using the formula ("1)

$$
\log D=5.17+1.46 M
$$

The cumulative deformation in the aftershock zone was also calculated and plotted as a function of time (Fig. 9).

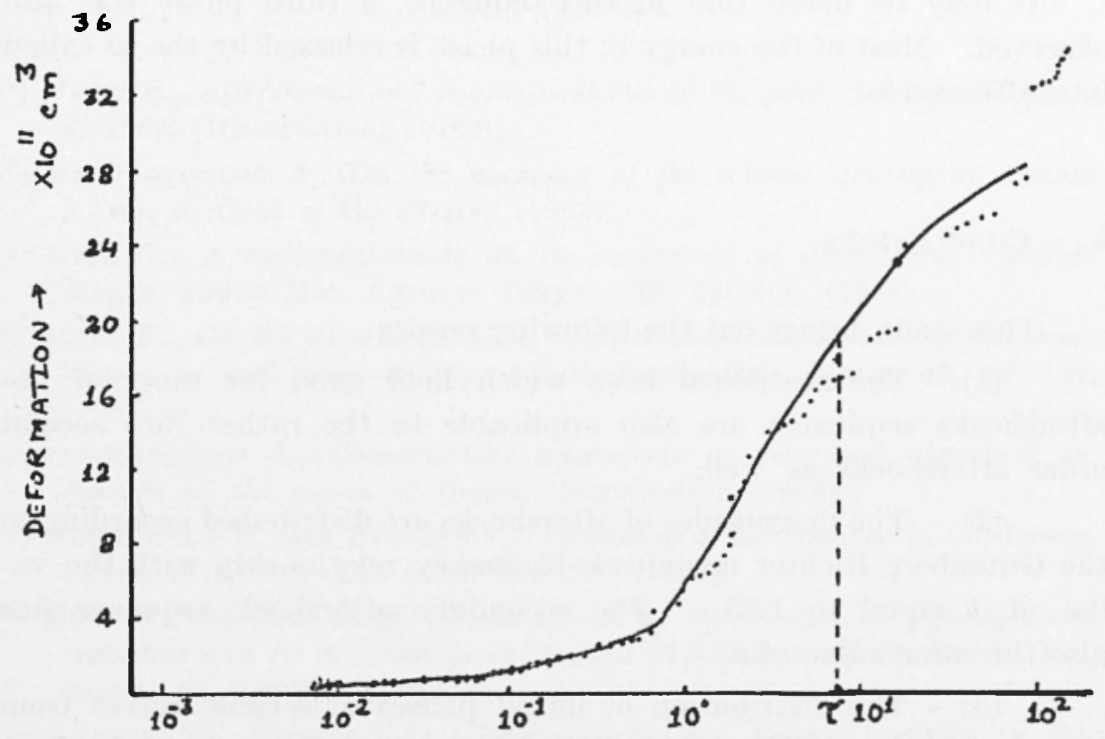

Fig. 9 - Deformation characteristics of the aftershock sequence.

The release of strain as noticed by Bath and Duda (21) occurs in two phases, the compressional and the shear. The energy in the compressional phase is released by small aftershocks. This phase commences immediately after the main shock. The shear phase starts a few hours after the main shock. Most of the energy in this phase is released by rather large aftershocks. The relaxation-time of the 
second phase is 8.0 days. Assuming that the relaxation-time $\tau$ is related with the coefficient of viscosity $\eta$ and the coefficient of rigidity $\mu$

$$
\tau=\frac{\eta}{\mu}
$$

we may estimate the value of $/$ using the above equation. The probable focal depth of these aftershocks is about $25 \mathrm{~km}$ and the velocity of the shear waves at this depth is approximately equal to $S_{y}$ velocity $\left(S_{\eta} \approx 4.55 \mathrm{~km} / \mathrm{sec}\right.$ in this region $\left({ }^{22}\right)$. Taking the density as $3.2 \mathrm{gm} / \mathrm{cm}^{3}$, the value of rigidity comes out to be $0.66 \times 10^{12} \mathrm{dynes} / \mathrm{cm}^{2}$. Thus the value of the coefficient of viscosity or better the mobility of the medium at this focal depth is of the order of $4.55 \times 10^{17} \mathrm{gm}$ $\mathrm{cm}^{-1} \mathrm{sec}^{-1}$ which agrees with that reported by Pshemnikov (17).

It may be noted that in this sequence, a third phase was also observed. Most of the energy in this phase is released by the so called late aftershocks.

\section{5. - Conciusions.}

This study brings out the following results:

(1) - The statistical laws which hold good for most of the aftershocks sequences are also applicable to the rather rare second order aftershockis as well.

(2) - The magnitudes of aftershocks are distributed according to the Gutenberg-Richter magnitude-frequency relationship with the value of $b$ equal to 1.25. The secondary aftershock sequence has also the same value of $b$.

(3) - The distribution of initial phases of seismic waves from the aftershock and the main shock shows marked similarity. However, the focal mechanism of the second order aftershock was found to be different from the main shock.

(4) - In addition to the compressional and shear phases as are generally observed, a third phase was also noticed. Most of the energy in the third phase was released by the major late aftershock.

(5) - The relaxation-time for the shear phase was found to be 8.0 days. The coefficient of viscosity in the region was estimated to be of the order of $4.55 \times 10^{17} \mathrm{gm} \mathrm{sec}^{-1} \mathrm{c}^{-1} \mathrm{~m}^{1}$. 


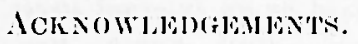

This research has been partially sponsored by the fir Force Office of scientific Reseneh under contract AF 61(052)-803 through OAR, United States dir Force.

The authors are grateful to Professor A. Galanoponlos, University of Athens for encouragement. The authors are very grateful to Dr. S. Omote, Director, International Tnstitute of Seismology and Earthquake Engineering, Tokyo, Japan, for providing the necessary facilities to carry ont the investigations presented in this paper.

\section{REFERENCES}

(1) PAGE R., Aftershocks and microaftershocks of the great Alaska earthquake of 196\%, [Dissertation, (1967)].

(2) Galanopoutos A., On the mapping of the seismic activity in Greece, "Ann. di Geof.", 16, 37-100, (1963).

$\left(^{3}\right)$ Utsu T., A statistical study on the occurrence of aftershocks, "Geoph. Magaz. Japan Met. Agency, Tokyo", 38, 521-605, (1961).

(") MOGI K., On the time distribution of aftershocks accompanying the recent Major in and near Japan, "Bull. Earth Res. Inst.", 40, 107-124, $(1962$, a).

$\left(^{5}\right)$ Drakopoulos J., Characteristic parameters of fore- and aftershock sequences in the region of Greece, [Dissertation (1968)].

(6) Gutenberg B. and Richten C., Frequency of earthquakes in California, "Bull. Seis. Soc. Anr. ", 34, 185.188, (1944).

(7) MoGI K., Study of elastic shocks caused by the fracture of Heterogeneous materials and its relations to earthquake phenomena, "Bull. Earth. Res. Inst. ", 40, 125-174, (1962, b).

( $\left.{ }^{8}\right)$ KARNIK V., Magnitude-frequency relation and Seismic activity in dijterent regions of the European Area, "Bull. Intern. Inst. of Seism. and Earth. Engineer. ", 1, 9-32, (1964).

( ${ }^{9}$ Galanopoulos A., Evidence for the seat of strain-producing forces, "Ann. di Geof. ", 18, 399-409, (1965).

(10) Papazacios B., Delibasis N., Liapis N., Moumoulimis G. and Purcaru G., Foreshock and aftershock sequences of some large earthquakes in the region of Greece, "Amn. di Geof.", 20, 1.93, (1967).

(11) SuYeinro S., ASAda T., and OIItake M., Foreshocks and aftershochs accompanying a perceptible earthquake in central Japan, "Papers Me. teor. Geophys. 'Tokso ", 15, 71-88, (1964). 
(12) MociI K., Some discussions on aftershocks, foreshocks and enthqualie swarms. The fraclure of a semi-infinile body caused by an internal stress origin and its relntion to enthqunke phenomena, "Bull. Sarth. Res. linst. ", 41, 615-658, (1963,b).

(13) U'su 'T., A methorl for determining the value of $b$ in the formula $\log n=$ a - bil showing the magnitude frequency relation for earthquakes (in Japanese with Jinglish abstract), "Geopl. Bull. Ilokkaido Univ. ", 13, 99-104, (1965).

(14) ROMNEY C. F., $1 n$ investigation of the relationship betueen magnilude scales for small shock, Proceed. Versia Conf. on seismic events magnilude determination, "Bull. Sci. and 'Tech. Univ. of Michigan ", 83-92, (1964).

$\left.{ }^{15}\right)$ UDras A., I study of the aftershocks and jocal mechanism of the SalinasIl atsonville Earthquales of August 31 and September 14, 19f3, "Bull. Seis. Soc. Am. ", 55, 58.106, (1965).

${ }^{(18)}$ MeEvilly T. V., The earthquake sequence of November 196t near Corralitos, California, "Bull. Seism. Soc. Am. ", 56, 755-773, (1966).

(17) Pshannikov N. K., The mechanism of aftershock development and the inelastic properties of the earth's crust, "Science Press", (1965).

$\left.{ }^{18}\right)$ Matuzawa T., Space distribution of aftershocks, "Seism. Soc. Japan.", 11, 15-24, (1936).

$\left.{ }^{19}\right)$ Psirensikov N. K., On plastic deformations within the earthyualie focus, "Tectonophysies ", 4, 3, 219-223, (1967).

$\left({ }^{20}\right)$ GutenberG B. and Ricirer C., Magnitude and energy of earlhquales, "Ann. di Geof.", 9, 1.15 (1956).

(21) BRTI M. and DUDA S. J., Earthquale volume, fault plane area, Seismic energy, Strain deformation and relation quantities, "Amn. di Geof.", 17, 353-368, (1964).

(22) Papazachos B., Cosminakis P. and Drakopoulos J., Preliminary results of an investigation of the crustal structure in southeastern Europe, "Bull. Seism. Soc. Am.", 56, 1241-1268, (1966). 